\title{
Schwannoma of the ciliary body treated by block excision
}

Michael Küchle, Leonard Holbach, Ursula Schlötzer-Schrehardt, Gottfried O H Naumann

\begin{abstract}
A 26-year-old man developed a non-pigmented ciliary body tumour of his right eye. A $7 \mathrm{~mm}$ block excision and tectonic corneoscleral graft were performed. The excised tissue was studied using histopathological, immunohistochemical, and electron microscopic techniques. The tumour revealed characteristic features of a Schwann cell neoplasm including Antoni $A$ and $B$ patterns, acid mucopolysaccharides, $S-100$, and vimentin positivity, and - by electron microscopy - Luse bodies. It was classified as a schwannoma. Although rare, schwannoma should be included in the clinical differential diagnosis of non-pigmented ciliary body tumours. Local excision should be considered to avoid overtreatment by enucleation.
\end{abstract}

(Br f Ophthalmol 1994; 78: 397-400)

Ciliary body schwannomas (neurilemmomas) are very rare benign peripheral nerve neoplasms. ${ }^{1-9}$ In two large histopathological studies that reviewed a total of 955 globes enucleated for uveal melanoma or pseudomelanoma, only one uveal schwannoma $(0 \cdot 1 \%)$ was found. ${ }^{40}$ Ciliary body schwannomas are frequently misdiagnosed as malignant melanomas resulting in unnecessary enucleation. ${ }^{12468}$ Therefore, we report the clinical, histological, immunohistochemical, and ultrastructural findings of a ciliary body schwannoma that was treated by block excision.

\section{Clinical history}

A 26-year-old white Turkish man presented with a prominent ciliary body tumour of his right eye. His medical history included inactive pulmonary tuberculosis but was of no help otherwise. There were no clinical signs of neurofibromatosis. For 3 years, the patient had noticed slight slowly progressive blurred vision of his right eye. Two years earlier, an 'iris cyst' of the right eye had been diagnosed and 'laser treatment' had been performed in Turkey. Corrected visual acuity was right eye $20 / 25$, left eye $20 / 32$, and intraocular pressure was right eye $18 \mathrm{~mm} \mathrm{Hg}$ and left eye $16 \mathrm{~mm} \mathrm{Hg}$. On examination, the left eye was completely normal except for anisometropic amblyopia. Slit-lamp examination of the right eye revealed a prominent, non-pigmented ciliary body tumour extending over 3 clock hours from 8 o'clock to 11 o'clock with erosion of the basal iris pigment epithelium. The tumour appeared solid with a smooth vascularised surface (Fig 1). Gonioscopy revealed a closed anterior chamber angle in the area of the tumour without tumour invasion into the anterior chamber or dispersion of tumour cells. The lens showed focal cortical opacification in the area of the tumour. There were no vitreous infiltrates, and the retina was flat without signs of shifting subretinal fluid. The optic nerve head appeared normal. A and B scan ultrasonography revealed a solid, homogeneous ciliary body tumour. Tumour prominence was 5 $\mathrm{mm}$. Aqueous flare measured with the laser flare cell meter was normal (6.7 photon counts/ms). Computed tomography or magnetic resonance imaging scan were not performed. The clinical differential diagnoses included adult medulloepithelioma and adenoma of the non-pigmented ciliary body epithelium. However, as a nonpigmented malignant melanoma could not be excluded, a $7 \mathrm{~mm}$ block excision of the ciliary body tumour including adjacent cornea, sclera, iris, and ciliary body was performed and the defect was closed with a corneoscleral graft. The postoperative course was complicated by vitreous haemorrhage which was treated by vitrectomy. Following vitrectomy, a traction retinal detachment developed which necessitated scleral buckling, membrane peeling, and sulphur hexafluoride gas tamponade. After this procedure, the retina was attached and corrected visual acuity was $20 / 100$.

\section{Material and methods}

The excised tissue consisted of cornea, sclera, ciliary body, and iris. A whitish solid ciliary body tumour. with a vascularised surface was present (Fig 2). Tumour diameter was $5 \mathrm{~mm}$, and tumour prominence was $5 \mathrm{~mm}$. The tissue was bisected radially and processed for light microscopy, immunohistochemistry, and transmission electron microscopy.

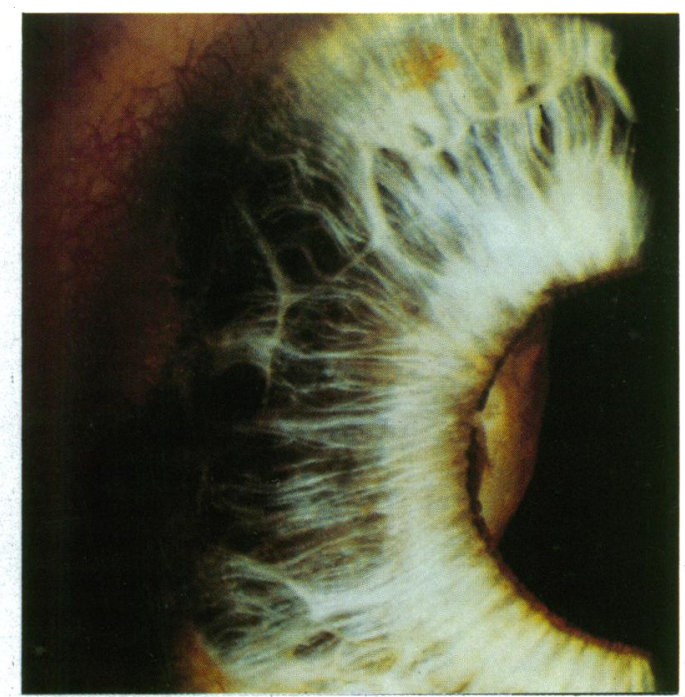

Figure 1 Slit-lamp photograph showing the ciliary body tumour in the patient's right eye. Notice the non-pigmented smooth tumour surface. 
Figure 2 Gross photograph of excised tissue consisting of cornea, sclera, ciliary body, and solid nonciliary body, and solid non(asterisk) measuring $5 \times 5 \mathrm{~mm}(\times 9)$.
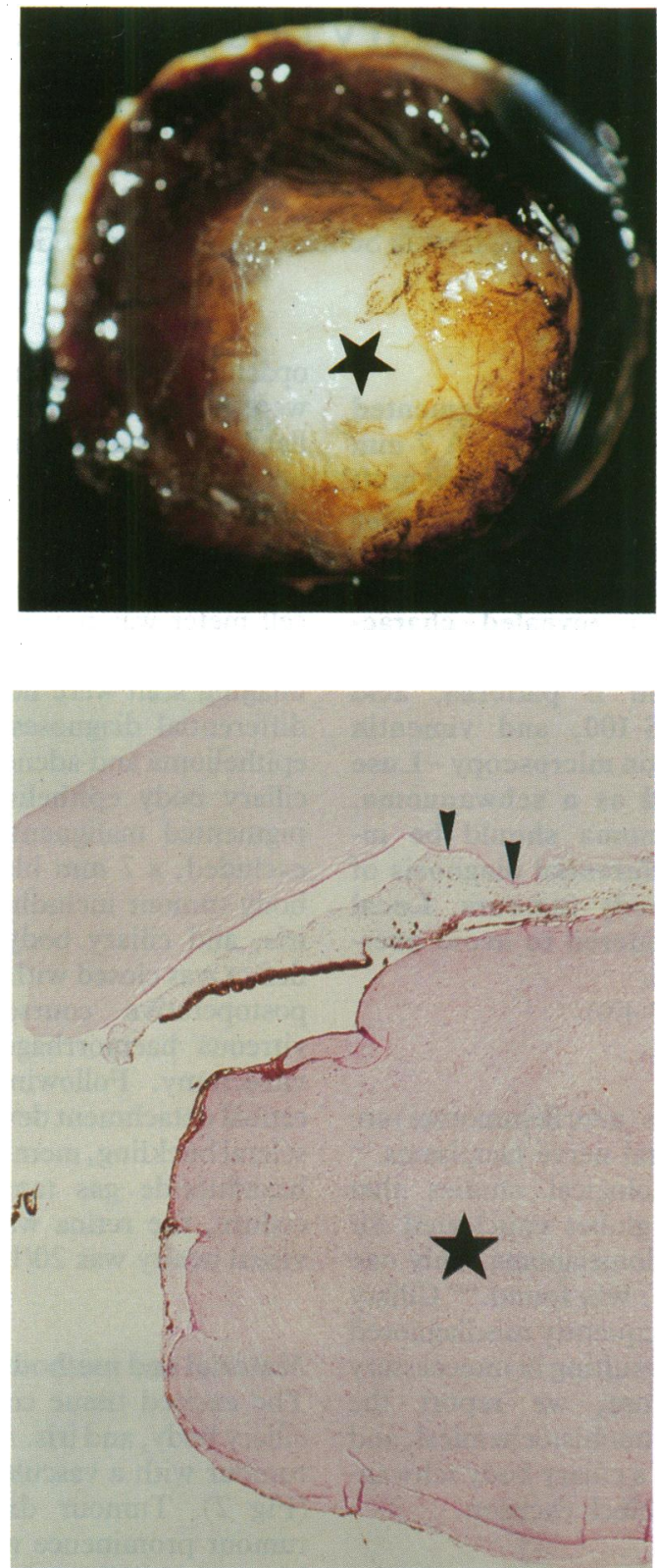

Figure 3 Photomicrograph showing ciliary body tumour (asterisk) and occluded chamber angle (arrowheads) (periodic acid Schiff, $\times 33$ ).

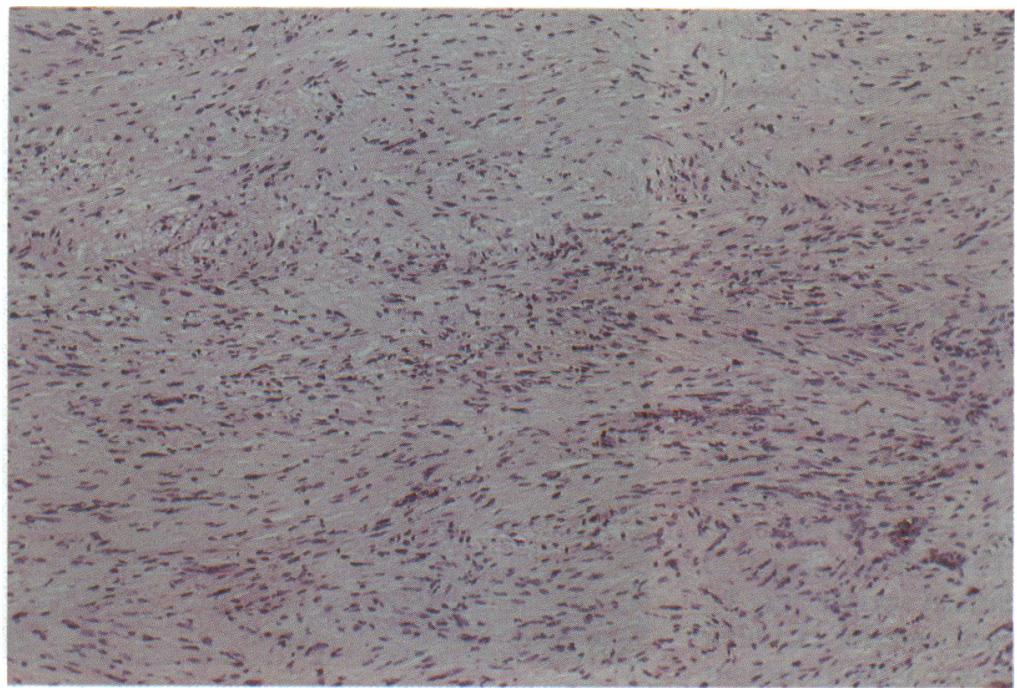

Figure 4 Photomicrograph of densely packed spindle shaped tumour cells showing fascicular arrangement (Antoni A pattern) (periodic acid Schiff, $\times 146$ ).

\section{Results}

Histologically, the chamber angle was closed (Fig 3). The ciliary body tumour was partially surrounded by a pseudocapsule and composed of spindle cells with rather small oval nuclei, eosinophilic cytoplasm, and small cytoplasmic extensions. Some areas of the tumour appeared solid with a densely packed fascicular arrangement of tumour cells (Antoni A pattern) (Figs 4, 5). In other areas, a loose, myxoid arrangement of tumour cells and extracellular mucoid substances were present (Antoni B pattern). The tumour cells appeared benign as the cells were uniform and mitoses or nuclear anomalies were absent. Using colloidal iron stains, acid mucopolysaccharides were demonstrated in the tumour. Immunoperoxidase staining showed tumour cell expression of S-100 protein and vimentin, whereas staining for desmin was negative. Transmission electron microscopy demonstrated spindle cells with electron lucent cytoplasm containing cytoplasmic filaments and sparse organelles (scattered mitochondria and lysosomes, short segments of rough endoplasmic reticulum) and long, delicate cytoplasmic processes (Fig 6). The tumour cells and their processes were covered by basement membrane material. Aggregates of banded basement membrane material (Luse bodies) were also present (Fig 7).

Given the histopathological, immunohistochemical, and electron microscopic findings, the diagnosis of a benign schwannoma (neurilemmoma) was made.

\section{Discussion}

Schwannomas (neurilemmomas) are benign nerve sheath tumours of Schwann cell origin. In ophthalmic patients, they arise most frequently in the orbit where they account for approximately $0 \cdot 5-1 \%$ of orbital tumours. ${ }^{11-13}$ Other periocular or ocular locations include the eyelids, ${ }^{14}$ the area of the nasolacrimal duct, ${ }^{15}$ conjunctiva, ${ }^{16}$ caruncle, ${ }^{17}$ limbus, sclera, ${ }^{18} 19$ choroid, ${ }^{20-23}$ and ciliary body. ${ }^{1-9}$ The development of ocular and periocular schwannomas may be associated with neurofibromatosis. ${ }^{2024}$

To our knowledge, a total of nine cases of ciliary body schwannoma have been reported so far. ${ }^{1-9}$ Six of those were clinicopathological case reports, ${ }^{125689}$ two were brief descriptions and illustrations in ocular pathology textbooks, ${ }^{37}$ and one was briefly mentioned in a study of lesions mistaken for uveal melanomas. ${ }^{4}$ Electron microscopic and/or immunohistochemical verification of the diagnosis was done only in four of the nine reported cases. ${ }^{6-9}$ As light microscopic differentiation of schwannoma from other benign spindle cell tumours and especially from neurofibroma is extremely difficult, and as the terms neurofibroma and neurilemmoma were not sharply separated before electron microscopy was available, the diagnosis of schwannoma in the early reports is probably somewhat uncertain. In none of the nine reported cases was a schwannoma suspected clinically, and seven of the nine eyes were enucleated because a malignant melanoma was suspected..$^{1-6-8}$

On clinical grounds, it is impossible to differ- 


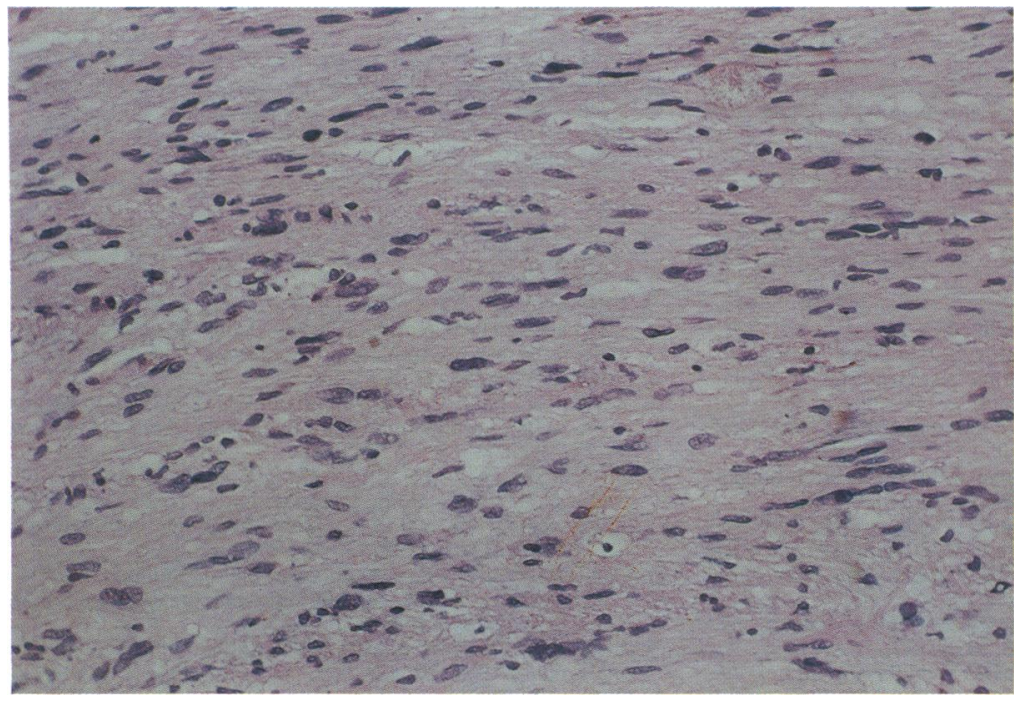

Figure 5 Higher magnification of tumour cells showing Antoni A pattern (periodic acid Schiff, $\times 294$ ).

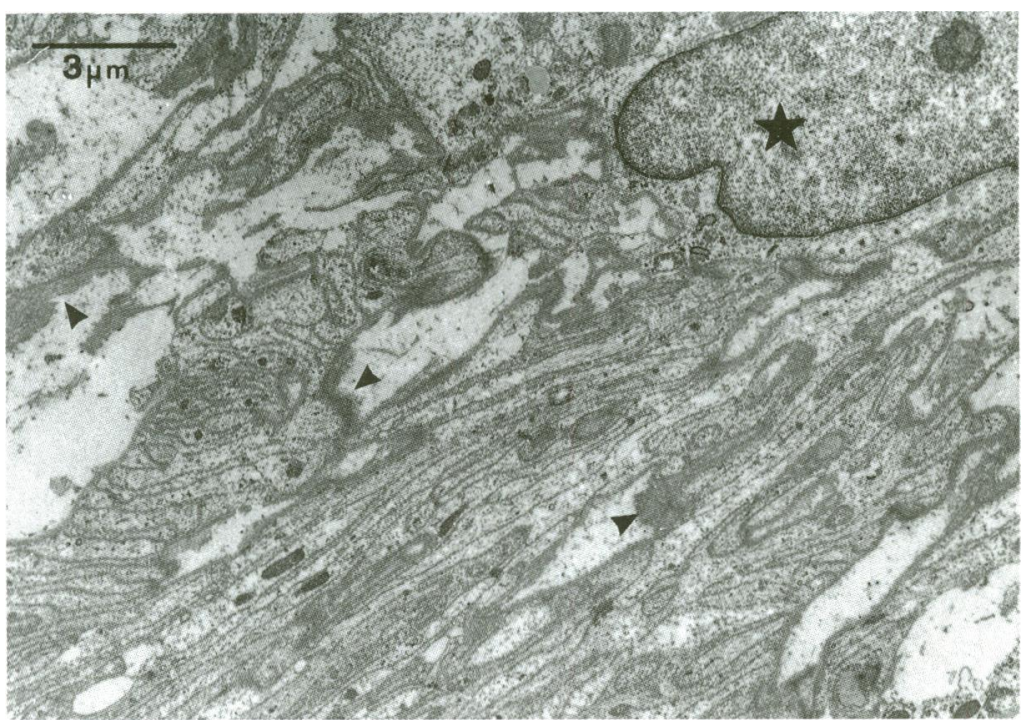

Figure 6 Electron micrograph showing closely packed and intertwined cell processes of Schwann cells. Schwann cell bodies and processes are diffusely covered by basal lamina (arrowheads). Asterisk indicates Schwann cell nucleus ( $\times 4785)$.

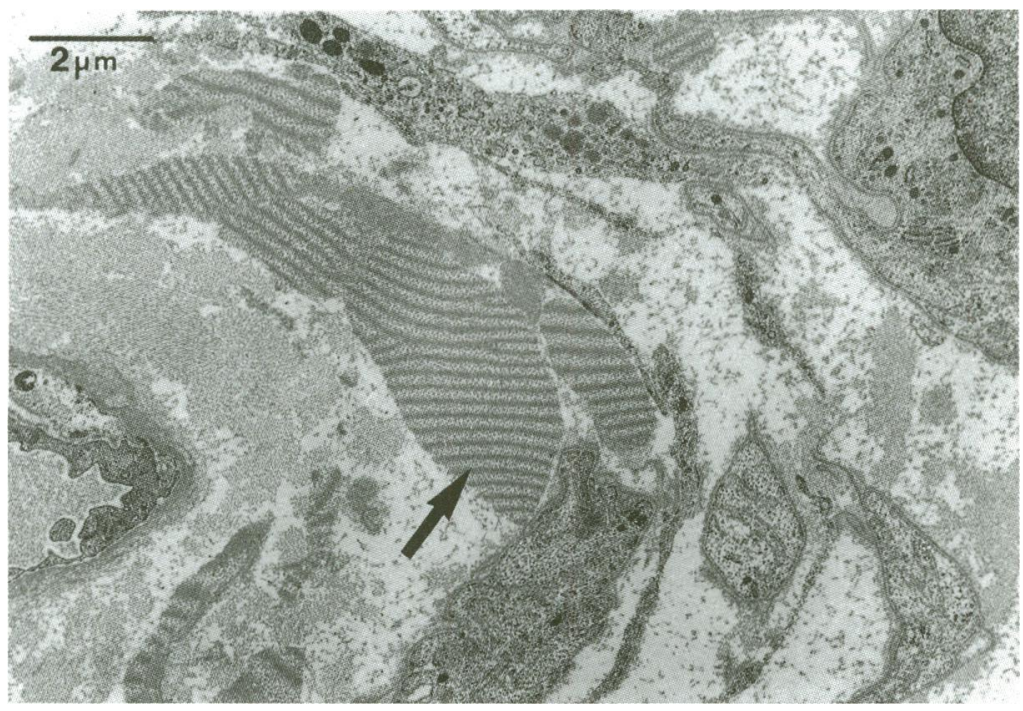

Figure 7 Electron micrograph of characteristic aggregate of banded basement membrane material (Luse body) (arrow) ( $\times 6195)$. entiate ciliary body schwannomas from other benign tumours such as leiomyoma, mesectodermal leiomyoma, adult medulloepithelioma, and adenoma of the non-pigmented ciliary epithelium. The most important differential diagnosis of ciliary body schwannoma is nonpigmented malignant melanoma, and it may be very difficult or even impossible to exclude a melanoma with certainty on clinical grounds. Clinical signs indicating malignant melanoma include rapid tumour growth, shifting subretinal fluid, invasion of the anterior chamber, and dispersion of tumour cells on the iris surface or throughout the chamber angle structures. Ancillary diagnostic studies such as fluorescein angiography, ultrasonography, computed tomography, and magnetic resonance imaging may be useful in the differential diagnosis. Noninvasive quantification of aqueous flare with the laser flare cell meter may also be helpful in the differential diagnosis of malignant and benign uveal lesions. It has been shown that aqueous flare is significantly increased in eyes with choroidal and ciliary body malignant melanomas. ${ }^{26}$ Interestingly, aqueous flare was in the normal range in our case. Fine needle biopsy and cytological examination may be another means of differentiating ciliary body tumours of unknown origin. ${ }^{27} 28$

Histologically, the tumour showed characteristics of a benign spindle cell tumour. For exact diagnosis, immunohistochemical studies and electron microscopy are required in addition to light microscopy. Electron microscopy displayed the characteristic findings of schwannomas including identification of Schwann cells with long cell processes and basal lamina long spacing basement membrane material referred to as Luse bodies. ${ }^{29-31}$ In our case, block excision of the ciliary body tumour with adjacent cornea, full thickness sclera, ciliary body, and iris was performed. ${ }^{32}$ Thereby, the tumour was removed in toto and enucleation was avoided.

Benign schwannoma should be included in the differential diagnosis of non-pigmented ciliary body lesions, and enucleation should be avoided in these cases. In prominent non-pigmented ciliary body tumours that are localised, extend over less than 6 clock hours, and do not show diffuse infiltration of the iris surface or chamber angle structures, block excision may be an appropriate therapeutic measure to remove the tumour in toto, allow histological diagnosis, and avoid overtreatment by enucleation or radiation.

The authors wish to thank Dr Ramon L Font for reviewing the histopathological sections, and Carmen Rummelt for substantial help in the immunohistochemical studies.

This study was supported by Förderverein für Augenheilkunde eV, Erlangen, Germany.

1 François J. Schwannome intraoculaire. Ann Oculist 1947; 180: $542-6$.

2 Donovan BF. Neurilemoma of the ciliary body. Arch Ophthalmol 1956; 55: 672-5.

3 Hogan MJ, Zimmerman LE, eds. Ophthalmic pathology: an atlas and textbook. 2nd ed. Philadelphia: Saunders, 1962, 443-5.

4 Ferry AP. Lesions mistaken for malignant melanoma of the posterior uvea. Arch Ophthalmol 1964: 72 463-9.

5 Rácz M, Szabó J. Zwei Fälle von Uvea anterior neurilemmoma. Klin Monatsbl Augenheilkd 1973; 163: 605-9.

6 Rosso R, Colombo R, Ricevuti G. Neurilemmoma of the ciliary body - report of a case. Br f Ophthalmol 1983; 67: 585-7. 
7 Green WR. Uveal tract. In: Spencer WH, ed. Ophthalmic patholog: an atlas and textbook. 3rd ed. Philadelphia: pathology: an atlas and textboo

8 Smith PA, Damato BE, Ko M-K, Lyness RW. Anterior uveal neurilemmoma - a rare neoplasm simulating malignant melanoma. BrF Ophthalmol 1987; 71: 34-40.

9 Hufnagel TJ, Sears ML, Shapiro M, Kim JH. Ciliary body neurilemoma recurring after 15 years. Graefes Arch Clin Exp Ophthalmol 1988; 226: 443-6.

10 Shields JA, Zimmerman LE. Lesions simulating malignant melanoma of the posterior uvea. Arch Ophthalmol 1973; 89: 466-71.

11 Kennedy RE. An evaluation of 820 orbital cases. Trans Am Ophthalmol Soc 1984; 82: 134-57.

12 Jakobiec FA, Font RL. Orbit. In: Spencer WH, ed Ophthalmic pathology: an atlas and textbook. 3rd ed. PhilaOphthalmic pathology: an atlas and

13 Bergin DJ, Parmley V. Orbital neurilemoma. Arch Ophthalmol 1988; 106: 414-5.

14 Shields JA, Guibor P. Neurilemoma of the eyelid resembling a recurrent chalazion. Arch Ophthalmol 1984; 102: 1650

15 Leib ML, Chynn EW, Michalos P, Schubert HD, Leib EJ Neurilemmoma of the anterior ethmoidal nerve encroaching upon the nasolacrimal duct. Br $\mathcal{F}$ Ophthalmol 1992; 76: $750-2$.

16 Vincent NJ, Cleasby GW. Schwannoma of the bulbar conjunctiva. Arch Ophthalmol 1968; 80: 641-2.

17 Rennie IG, Parsons MA, Benson MT. Neurilemoma of the caruncle - a clinicopathological report. Br $\mathcal{f}$ Ophthalmol 1991; 75: 749-51.

18 Quintana $M$, Lee WR. Intrascleral schwannoma. Ophthalmologica 1976; 173: 64-9.

19 Graham CM, McCartney ACE, Buckley RJ. Intrascleral neurilemmoma. Brf Ophthalmol 1989; 73: 378-81.

20 Vannas S, Raitta C, Tarkkanen A. Neurilemmoma of the choroid in Recklinghausen's disease. Acta Ophthalmol (Suppl) 1974 ; 123: 126-33.
21 Brewitt H, Heurkamp B, Richter K. Ein Neurinom der Aderhaut-Überlegungen zur klinischen Differentialdiagnostik. Klin Monatsbl Augenheilkd 1976; 169: 750-4.

22 Packard RBS, Harry J. Choroidal neurilemmoma - an unusual clinical misdiagnosis. Br f Ophthalmol 1981; 65: 189-91

23 Shields JA, Sanborn GE, Kurz GH, Augsburger JJ. Benign peripheral nerve tumor of the choroid - a clinicopathologica correlation and review of the literature. Ophthalmology 1981; 88: 1322-9.

24 Bickler-Bluth ME, Custer PL, Smith ME. Neurilemoma as a presenting feature

25 Freedman SF, Elner VM, Donev I, Gunta R, Albert DM. Intraocular neurilemmoma arising from the posterior ciliary nerve in neurofibromatosis - pathologic findings. Ophthalmerve in neurofibromatosis

26 Küchle M, Nguyen NX, Naumann GOH. Aqueous flare in eyes with choroidal malignant melanoma. Am $\mathcal{f}$ Ophthalmol 1992; 207: 113-4

27 Augsburger JJ, Shields JA, Folberg R, Lang W, O'Hara BJ, Claricci JD. Fine needle aspiration biopsy in the diagnosis of intraocular cancer - cytologic-histologic correlations. Ophthalmology 1985; 92: 39-49.

28 Char DH, Miller TR, Crawford JB. Cytopathologic diagnosis of benign lesions simulating choroidal melanomas. Am f Ophthalmol 1991; 112: 70-5.

29 Luse SA. Electron microscopic studies of brain tumors. Neurology 1960; 10: 881-905.

30 Sian CS, Ryan SF. The ultrastructure of neurilemoma with emphasis on Antoni B tissue. Human Pathol 1981; 12: $145-60$.

31 Erlandson RA, Woodruff JM. Peripheral nerve sheath tumors - an electron microscopic study of 43 cases. Cancer 1982; 49: 273-87.

32 Naumann GOH, Völcker HE, Gäckle D. The block excision of malignant melanomas of the ciliary body and the periphera choroid. Doc Ophthalmol 1980; 50: 43-8. 